\title{
New Challenges in Public Health Practice: The Ethics of Industry Alliance with Health Promoting Charities
}

\author{
Nathan Grills \\ University of Melbourne \\ Australia
}

\section{Introduction}

In an increasingly market driven society, characterised by neoliberal economic policies and promotion of free trade, powerful multinationals have become significant actors, for good and bad, in global public health. These powerful multinational companies are using increasingly sophisticated marketing strategies not only to promote products - some of which are deleterious to health - but also to lobby against public health initiatives that threaten their profit. Should public health practitioners cooperate with, or even attempt to coopt, these powerful organisations in an endeavour to promote health? Although this seems to be an increasing trend one must remain cogniscent that these companies will promote profit at the expense of health and often they are more effective at coopting health causes for their profit driven purposes than health causes are at coopting them for public health ends (Wright 2010).

In particular, this chapter explores how sponsorship of charities by corporates is actually a form of advertising that, when unhealthy products are promoted, can damage public health. The favoured approach by industry to minimise negative impacts of such advertising is via self regulatory codes. However, in Australia and elsewhere, these have by and large failed (Handsley E, Nehmy C et al. 2007; Ofcom 2008; National Preventative Health Taskforce 2009, p151; World Advertising Research Centre 2009). For example, in Australia the voluntary self regulatory policy to limit advertising of unhealthy products to children, called the Quick Service Restaurant Industry (QSRI), has resulted in no meaningful change since being introduced in 2009. The New South Wales Cancer Council concluded that "Children's exposure to unhealthy fast-food advertising has not changed following the introduction of self-regulation" (Chapman, Hebden et al. 2011). Is it time for policy makers to impose limits on the promotion of unhealthy products in order to protect the health of the public.

It is not so surprising that self regulation initiatives fail as it is counter intuitive, and against shareholder interests, for a profit seeking industry to minimise profit through self regulation. For example, arround $50 \%$ of profit from gambling comes from those who are being harmed by the product: "problem gamblers" (The Public Health Association of Australia 2008). Therefore limiting advertising of unhealthy products in order to remove damage to health would threaten the viability of such industries and that outcome is definitely not in the interests of the shareholders! 
In relation to corporate funding of health charities this seems to be entirely unchecked by either government or industry self regulation. At the very best this approach involves fundraising for a good cause that would otherwise be underfunded, and no doubt the charities themselves have no other motivation than to see their important cause supported. However, cynics of Corporate Social Responsibility (CSR) would argue that the ultimate goal for industry is profit, or at the very least trying to mitigate criticism of the organisation (Wright 2010). At its most sinister, might CSR involve an ethically questionable model whereby the charity is exploited to promote a company whose product is deleterious to health? This chapter describes how unethical behaviour increases along a spectrum when using charities to advertise by:

1. Funding a charitable cause in order to advertise a product

2. Funding a children's charity to advertise a product

3. Funding a children's charity to promote a product that causes harm

4. Funding a children's charity to promote a product that causes the very illness that the charity seeks to respond to

5. Funding a children's charity to promote a product that causes the very illness that the charity seeks to respond to, and use this sponsorship to attain the high moral ground and lobby against public health approaches to address the public health problem

Although there are various international case studies one could cite (see www.cmaj.ca/cgi/content/full/cmaj.110085/DCI for a list) this chapter unpacks four examples demonstrating potentially unhealthy alliances where industry has seemingly coopted children's charities and public causes in order to sell a product that damages health. This discussion attempts to raise awareness about such subtle marketing and intends to help readers discern what might be appropriate and inappropriate use of charitable causes.

Ultimately, we would hope that reading this chapter leads the reader towards taking action to protect our most vulnerable consumers from powerful industry interests. The chapter finishes by exploring how those in public health can creatively engage with this issue and respond by even using many of the same tactics utilised by companies whose products damage health.

\section{What is an acceptable form of company sponsorship of health charities?}

Advertising and marketing is very effective at selling 'goods', but these goods are not necessarily good. In the area of marketing Energy Dense and Nutrient Poor Food and Beverages (EDMPFB) various international reviews have concluded that heavy marketing is likely to have deleterious effects on children by encouraging products high in salt, sugar and fat (World Health Organization 2003; Livingstone 2006; National Preventative Health Taskforce 2009). Accordingly, in many countries, various codes exist to regulate marketing. However, Australian restrictions have been largely voluntary self-regulated codes which have failed to prevent ethically questionable advertising, such as advertising to children (Hebden, King et al. 2011) (Chapman, Hebden et al. 2011).

On the surface it seems acceptable, or even desirable, that a company whose product causes damage should contribute to alleviation of the same damage. Such is the basis for carbon credits and taxes whereby companies contributing to carbon production may choose, or be required, to contribute towards mitigation of the problem to which they contribute. An 
example from the health field is DrinkWise, a charity funded by the alcohol industry, aiming to shape "a healthier and safer drinking culture in Australia where drinking to excess, or drinking too young, is considered undesirable". Such recompense is desirable if the aim and the effect is mitigation.

However, sponsorship is ethically tenuous when a company whose product potentially causes illhealth, assists victims, and in doing so advertises the very product that caused the illhealth. Libertarians would argue that companies should be entitled to pursue such strategies, as informed adults are capable of discernment and can decide accordingly.

However, there is a flaw in the assumption of consumers being fully informed or having the necessary agency to make such distinctions. For example, are people aware that DrinkWise is industry sponsored and have been accused of promoting the very products that caused the harm they are seeking to mitigate? The consumer may be unable to make a fully informed choice if the true identity of the organisation is unclear. If company $X$ sponsors a charity $Y$ which addresses the ill-health caused by the same company $X$, then consumers should surely be informed that charity $\mathrm{Y}$ is supported by Company $\mathrm{X}$ whose product causes the ill health.

However, it seems more ethically objectionable when a company whose product could harm children, then assists the children who might be harmed, to make these children consume more of their potentially harmful product. Not only is a potentially harmful product being advertised to children, but the immature target audience, unaware of the danger of the product being marketed, could be influenced to view it as harmless or even good. Acknowledging the effect of advertising unhealthy products to children, Australia's National Public Health Task Force (NPHTF) recommended phasing out of "premium offers, toys, competitions and the use of promotional characters, including celebrities and cartoon characters, to market EDNP food and drink to children across all media sources". Similar moves have been initiated in other countries (Handsley E, Nehmy C et al. 2007; Ofcom 2008; National preventative health taskforce 2009, p151; World Advertising Research Centre 2009) (World Health Organization 2003; Livingstone 2006): Sweden and Norway prohibit commercial advertising directed at children via television, and Quebec prohibits the use of any media (Handsley E, Nehmy C et al. 2007, p153).

Perhaps even more insidious is where the funding of worthy charities creates an unhealthy alliance which allows a company to attain the moral high ground, and so limit their vulnerability to challenges regarding their unhealthy products and questionable practices. For example, if a policy-maker decided to limit a company's ability to inappropriately market their product to children, the company might then generate popular opinion against the politician with arguments like "this will undermine our ability to support children's charities such as the Ronald McDonald kids health truck!" (Prisk 2011). This supports a concept described in the literature where Corporate Social Responsibility, such as sponsoring a charity, is really about company credibility and positioning in order to benefit their bottom line (Wright 2010), or as Wright describes, limited to where it is profitable and often as a reaction to criticism of their product and practices. An example of ethically questionable practices might involve sponsoring a children's organisation to divert attention away from a product that potentially harms children.

I will outline four case studies which demonstrate that this practice might be more common than we perceive. Each case study may represent the intentional use of CSR to gain moral 
high ground and sell potentially harmful products, or may be merely coincidental. Either way these practises need to be challenged.

\subsection{Case study 1: The Donut King alliance HeartKids}

The Donut King has become a regular supporter of HeartKids which is a foundation to support children with heart diseases and their families. On a single day in 2011 they kindly offered to give 50 cents of every purchase of a coffee from their fast food chain to the HeartKids charity. Of course this was promoted widely through adverts and in store promotion that cobranded Donut King products with the HeartKids logo (HeartKids 2011). Many readers would not initially discern any problem with Donut King supporting such a worthy charity, but the partnership warrants closer scrutiny.

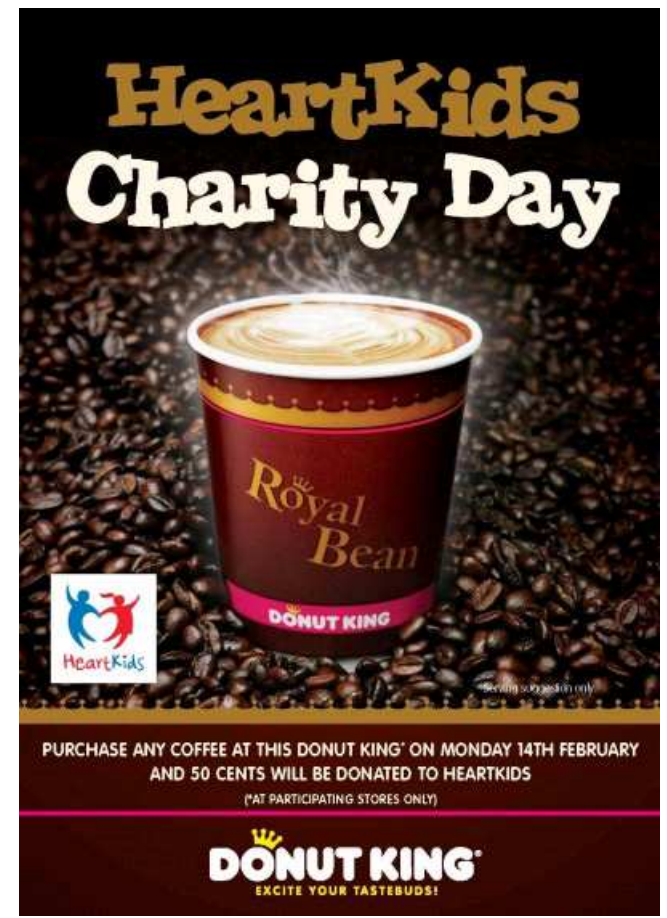

Doughnuts are Energy Dense and Nutrient Poor Food and Beverage (EDNPFB) foods and such foods are linked with childhood obesity and cardiovascular disease later in life (National preventative health taskforce 2009). Whilst adults might be aware that doughnuts are potentially damaging EDNPFB and that sponsorship of a charity might actually be advertising, children may not be (HeartKids 2011). Additionally, children may be incapable of disentangling the apparent contradiction of an advertisement that links a fast food chain selling unhealthy food that can ultimately damage hearts, with a charity promoting healthy hearts in children! Is such advertising ethical if it exploits our most vulnerable community members: children and their health? 
Indeed, such sponsorship can divert attention away from the potential harms of this company's EDNPFB whilst also attaining a moral high ground. That is, any challenge to the Donut King's charitable sponsorship - probably including this challenge - will immediately draw a response such as "Get a heart! Are you saying we shouldn't support HeartKids"! Interestingly, a medical colleague originally forwarded me this advertisement and encouraged us to visit Donut King to support HeartKids. I couldn't easily express my disapproval to her given that her child suffered congenital heart disease and would potentially benefit financially by the sponsorship.

The objection was not that children with congenital heart disease are harmed by Donut King's product and, indeed, most children with congenital heart disease need a high calorie intake. However, looking beyond the individual level, is there a population effect of normalising such unhealthy products? Through such sponsorship the Donut King is promoted as a good citizen who cares about health, and its products might be widely associated with a health cause, both of which may potentially increase sales of unhealthy products population wide. Secondly, even if the population effect is small, is it ethically appropriate to promote unhealthy products using vulnerable children to convey a message that this company cares about the very hearts that their product may damage?

\subsection{Case study 2: McDonalds' alliances with the Royal Children's Hospital (RCH)}

McDonald's relationship with the $\mathrm{RCH}$ Melbourne permits them to have a fast-food franchise on the hospital's grounds (Royal Children's Hospital 2010). The EDNPFBs that McDonalds promote are linked with childhood obesity and ill-health. In the famous UK libel case McDonalds sued two individuals for disseminating brochures claiming that McDonalds, amongst other things, was bad for health. The UK court of appeal found that "there is a respectable (not cranky) body of medical opinion which links a junk food diet with a risk of cancer and heart disease' and 'this link was accepted both in the literature published by McDonalds themselves and by one or more of McDonald's own experts and in medical publications of high repute'"' (Judgement, p169).

Granted, McDonalds at $\mathrm{RCH}$ is much appreciated by parents and children alike, making the perfect sweetener for a child facing the trauma of visiting hospital. I also confess that as a father of a chronically unwell child, after leaving the ward at $10 \mathrm{pm} \mathrm{I} \mathrm{have} \mathrm{visited}$ McDonalds to wind down in a friendly environment. However, I could have just as easily wound down in whatever cafe or restaurant was still open and accessible. Additionally, the government has stepped in to require the McDonalds at the new $\mathrm{RCH}$ to provide $80 \%$ healthy foods choices (green and amber) whilst restricting unhealthy food choices to $20 \%$ (Royal Children's Hospital 2010).

Yet the concern around McDonalds in the $\mathrm{RCH}$ is more complex than the negligible health impact on individual parents or children visiting McDonalds on a few random occasions whilst receiving care. There are ethical concerns about this alliance. Firstly, McDonalds can use their sponsorship to promote their brand name and unhealthy products to children and the wider community. This normalisation of EDNPFB consumption in the wider community is hazardous given that childhood obesity is approaching 30\% in Australia. Secondly, is it ethically acceptable to allow our most vulnerable children to be exploited for the marketing of potentially unhealthy and harmful products? We allow these companies to promote an 
image of a company which cares about the very children that their product may harm. Finally, is it acceptable to allow McDonalds or Donut King to attain the moral high ground by affiliating themselves with children's healthcare institutions and causes? It is very difficult to oppose unhealthy practices and products when these 'good corporate citizens' are seen to be promoting children's health.

So why do we allow an organisation whose product may damage children's health to sponsor our children's hospital? Are there other 'healthier' organisations which could support the $\mathrm{RCH}$ ? I would like to reiterate Margaret Chan's challenge to such companies: "I would like to ask the food and beverage industries. Does it really serve your interests to produce, market, globally distribute, and aggressively advertise, especially to children, products that damage the health of your customers?"(Chan 2011). Again, such a case is difficult to sustain given outrage generated by threatening funds for children's healthcare (Prisk 2011). McDonalds are very safely on the moral high ground.

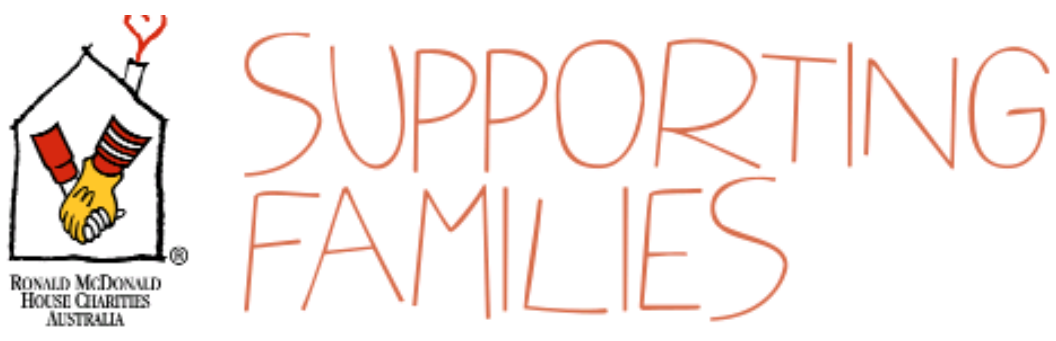

\section{Ronald McDonald House Charities}

Ronald McDonald House Charities $\otimes(R M H C \otimes)$ has been helping seriously ill children and their families since 1981.

How can one argue against "supporting families" and "helping seriously ill children"?

\subsection{Case study 3: Tattersall's alliance with the RCH}

Would you allow the following company to speak to your kids when the company has a majority stake in an industry which:

- Makes more than $50 \%$ of their profit by trapping powerless addicts (Hancock, Schellinck et al. 2008)

- Profits from the most vulnerable and poorest

- Increases crime rates in the area (study reported in the Age, July, 2010)

- Impoverishes and breaks up thousands of families in Australia each year

- Is associated with one in five suicide attempts in patients presenting to the Alfred Hospital in Melbourne

Most responsible parents would not allow such companies to promote their product to their children, so why does RCH allow Tattersall's to do so in the Children's Hospital? A RCH Foundation report provides an answer: 
“The ongoing contribution of Tattersall's, one of the hospital's longest standing corporate partners, has reached a total of $\$ 8$ million. Each and every dollar that comes into the Foundation represents both personal sacrifice and the affectionate regard that Victorians have for the Royal Children's Hospital." (Royal Children's Hospital 2010).

This outlines both the reasons for the link ( $\$ 8$ million) and also demonstrates the moral high ground obtained in that every dollar from Tattersall's "represents both a personal sacrifice and affectionate regard". How can one question a donor who has an affectionate regard for an important institution like the $\mathrm{RCH}$ ? Such organisations can use their moral high ground to influence policy as was shown in the recent senate committee investigation into gaming where Woolworths, the biggest owner of electronic gaming machines, threatened that they would have to decrease their investment in the community if profits from electronic gaming machines were limited by legislation (Needham 2011 (Feb 11)). Perhaps the new RCH, "completed in 2011", might reconsider this unhealthy association?

The community needs to recognise that the products that Tattersall's promotes actually cause significant harm to the very society that it claims to be helping through its support of charities. One expert researcher in the field, Professor Charles Livingstone argues:

"The problems of pokie gambling are not trivial. They include financial distress and ruin, bankruptcy, fraud, embezzlement, and theft and misappropriation of the funds, property and income of family, friends, employers and others. Gambling problems are also strongly associated with crime generally, family breakdown, divorce, the neglect and abuse of children, mental and physical illness, depression and anxiety, and not infrequently include suicide. The children of regular and problem gamblers are themselves significantly more likely to have a gambling problem than those of nongamblers, and poker machine venues are most strongly concentrated in poorer suburbs"(The Public Health Association of Australia 2008).

However, despite Tattersall's association with such damage, it has represented itself by sponsoring the very society that it harms. Tattersall's do not only sponsor children's hospitals and hospital emergency departments in Australia but various sporting clubs in which our children participate. Many sporting clubs have become dependent on the revenue from sponsorship of Gambling agencies or from revenue from owning gaming machines. There is little doubt that allowing the gambling industry to operate in sports clubs exposes children to advertising and normalisation of such products. Do we need better protection? However, once again the gambling agencies have attained the moral high ground where clubs and supporters may well contest that the club depends on that revenue. If we ban the "Tattersals' sponsorship" then we risk accusations of compromising institutions that actually promote health. In Australia McDonalds has similarly inserted itself into the health DNA of our schools and youth clubs through sponsoring Auskick, kids sporting events and, at a higher level, sponsoring Australian international sporting teams such as the Australian Olympic Team. The Australian Olympic Team website allows McDonalds to boast "In Australia, we are very proud to be helping kids be active by supporting Little Athletics, Soccer, and Basketball in various states" (http://corporate.olympics.com.au/sponsor/mcdonalds) 


\subsection{Case study 4: Alcohol industry alliance with children's fundraising}

There is good evidence that exposure to alcohol advertising shapes young adolescents' attitudes toward alcohol, their intentions to drink, and underage drinking behaviour (Martin 2002). Additionally, studies show that alcohol advertisements are often shown during the shows that target teens such as sporting events (Martin 2002). In Australia, thankfully, alcohol advertisements are no longer shown during children's programs. However, alcohol advertisements do still target youngsters during shows watched by large numbers of children such as sporting events. In 2002, in the US, over a billion dollars was spent to advertise alcohol on TV and around $22 \%$ of these advertisements were seen more by youth than adults (Center on Alcohol Marketing and Youth 2004).

Similarly to Tattersall's and McDonalds, alcohol companies do not only advertise through traditional media platforms. The alcohol industry has been a regular sponsor of sporting and charity events held through our schools. This can achieve a similar end to more traditional forms of advertising. A recent report by the Australian National Council on Drugs found that alcohol was often the focus of various fundraisers which include supporting wine "drives" conducted via newsletters, liquor "tasting events" on school premises, and alcoholic bottles featuring school logos. Dr Herron from the Australian National Council on Drugs states:

"I think we all know subliminal messages have a huge impact on young people. Through attaching (fundraisers) to a school newsletter, we're legitimising them and saying it's all right for students to be transporting information about alcohol between the home and school." (Barry 2011)

Again it must be questioned if such charitable sponsorship is benevolent or little more than blatant advertising to adults and children by profit driven alcohol companies.

However, the involvement of charitable causes makes rational debates on this issue difficult to have. Few critics of advertising to children would doubt that well meaning parents and friends have the best intentions in raising funds for worthy causes. Indeed, the alcohol companies take advantage of this very fact to, once again, attain the moral high ground and an immunity to being challenged. Parents and friends become a powerful ally for the alcohol companies and might well defend the company by passing off the 'sponsorship' as harmless and merely for philanthropic purposes.

Similarly to the first three case studies, we again question if it is ethical to allow an alcohol company to link itself to a school when damage from youth alcohol usage is so prevalent and damaging throughout Australian society (Chikritzhs, Pascal et al. 2004). The list of damage caused to youth by alcohol is long and well established but can be best summarised by the fact that Alcohol accounts for $13 \%$ of all deaths among people 14-17 years of age and in Australia, each week, one teenager dies and around 60 are hospitalized from alcoholrelated causes (Jones, Chikritzhs et al. 2004; Clark, Thatcher et al. 2008). Teenagers without the benefit of good judgement from experience, are particularly vulnerable to alcohol related harm in a way that older drinkers may not be (Australian Medical Association 2009). Among young Australians, the most common causes of death and injury due to risky or high-risk drinking are road injury, suicide, and violent assault (Chikritzhs, Pascal et al. 2004). The Australian School Students' Alcohol and Drug Survey (hereinafter ASSAD) 
highlights the extent of the alcohol problem amongst youth with $13 \%$ of children aged 16 year olds having drunk at dangerous levels in the past week (Centre for Behavioural Research in Cancer 2008).

As these statistics suggest, allowing companies to insert themselves into schools is self evidently unacceptable but the alcohol industry inserts itself more insidiously into children's health causes outside the school environment. The AMA documents how the increasingly sophisticated marketing of alcohol is aimed at attracting, influencing, and recruiting new generations of potential drinkers (Australian Medical Association 2009). One example is the targeting and supporting of not-for-profit Australian sporting clubs by alcohol companies. Children involved in these clubs grow up viewing alcohol advertisements and conceivably accepting the industry as an important part of their society and a promoter of good health. Nothing could be further from the truth given that alcohol is one of the greatest dangers faced by the young people of Australia! Furthermore, alcohol, from whatever perspective you look at it, is damaging to sporting performance so it is ironic, or maybe intentional, to link a health damaging product to health promoting activities. Instead such support of charities by the alcohol industry would seem to be another example of an industry injurious to children's health allying itself with children's charities in order to promote its product and image.

\section{Why is it unethical?}

To help determine if a sponsorship is ethical it is also worth referring to the stewardship model outlined in the report by the Nuffield Council on Ethics (2007). They concluded that in regards to the role of industry, the media and other parties, "businesses have obligations towards society. Many businesses already have social responsibility policies. Where industries fail to meet reasonable standards it is acceptable for the state to intervene through regulations (Paragraphs 2.47-2.50 and 3.41)". If the above case studies represent failure to meet acceptable standards, then should the state government intervene to limit this sponsorship?

Secondly, when promotion of unhealthy products involves children, through the use of children's health institutions and charities, the mandate for action is clearer. The stewardship model outlines "protecting and promoting the health of children and other vulnerable groups" as a high order principle that can justify limiting freedoms (Nuffield Council on Bioethics 2007). It would seem that allowing companies to exploit children's charities to promote harmful products would go against the stewardship model. In effect children represent a market failure due to imperfect information and information asymmetry as they are incapable of being fully informed consumers. We therefore have an ethical mandate to steward our most vulnerable by protecting them against exploitation.

Permitting companies to exploit children's charities and children's health services to promote harmful products might qualify as "behaviour harming others". According to J.S. Mill, in his famous volume 'On liberty', intervention by the state is only justified when behaviour harms others, as such sponsorship might do if it causes more consumption of the harmful products (Mills 1909). Similarly a recent article in the Lancet argues "Liberty should be restricted, in a liberal society, only when there is a clear and direct threat of harm to 
innocent parties who cannot respond for themselves" (Finn and Savulescu 2011). There seems adequate evidence now that advertising of unhealthy products to children does cause harm to children who are incapable of responding.

The intervention ladder developed under the Nuffield Bioethics report holds that more intrusive interventions require stronger justification. Although the ethics of advertising to children is still being contested, we conclude that allowing companies promoting unhealthy products to link their product to health institutions or causes, is a justification for action.

Regulating advertising to children is gathering widespread support in Australia where consumers (or more accurately the parents of consumers) are tired of having to fight against blanket advertising to maintain healthy diets for their children. Key findings from a recent phone survey is South Australia were:

- $85 \%$ of consumers believe children should be protected from unhealthy food advertising.

- $\quad 93 \%$ of people were in favour of the government introducing stronger restrictions to reduce the amount of unhealthy food and drink advertising seen by children, with $79 \%$ strongly in favour.

- $86 \%$ of grocery buyers are in favour of a ban on advertising of unhealthy foods at times when children watch TV, with $70 \%$ strongly in favour.

- When asked what most commonly negatively impacted their children's food purchase requests, grocery buyers reported television commercials $(36 \%)$ or toys and giveaways $(24 \%)$.

(Cancer Council SA 2011)

Along these lines of protecting minors, the Gambling Regulation Act 2003 (Vic) would seemingly be justified in seeking "to ensure that minors are neither encouraged to gamble nor allowed to do so" (section 1.1.iib) (Victorian Government 2003). This act therefore challenges Tattersall's promotion of their brand at the RCH.

\section{What action should be taken?}

If such behaviour is proceeding with little regulation in many countries then what can be done? I suggest a similar approach to what has worked in previous campaigns such as the one to limit tobacco companies' right to advertise their harmful product. It has taken a concerted, multipronged and sustained campaign to undermine the supposed right to advertise this dangerous product. This included advertising, mobilising physicians around the cause, raising public awareness, undertaking research and advocating to the policy makers and key stakeholders.

Firstly we believe that public health practitioners and doctors should raise awareness of potentially unethical approaches. Doctors and the health profession more generally are still widely respected by the community. As professionals concerned for the health of those in our community we must be making efforts to protect the health of our most vulnerable. At the very least, awareness can be raised in the public health arena by writing to media outlets, journals and other fora in order to expose, or at least question, apparent unhealthy alliances. Such lobbying has been shown to be an important part of a 
concerted campaign, and effective when it is part of a multipronged approach. The use of the new media is also important. A website called unhealthyalliances is under development. A campaign in Canada drew on a Facebook group to undermine the Burger King's placement of its product in a children's hospital.

In particular, health professionals should advocate for the banning of advertising of damaging products in children's hospitals and institutions where they work. After all, the problem is not primarily related to the companies, which are by nature profit driven. Instead the onus falls largely on the health organizations themselves where many of us work. We should be continually challenging our employers towards more ethical behaviour by dissuading them from accepting money from, and partnering with, companies whose products damage children's health. We should not accept ethical standards being compromised merely in order to finance health programs, buildings and services. In Toronto staff contributed to preventing the Burger King from continuing to operate at the Sick Kids Hospital. The group drew comments from physicians and health professionals to add pressure not to renew the Burger King's lease despite the \$2.5million the Burger King had raised for the hospital (Farquharson 2011, March 20).

Physicians who sit on boards and advise on hospital governance issues need to avoid being complicit by not taking action. They can advocate for regulations and clauses to limit the food industry exploiting children. An article in the CMJ advises that at the very least "partnerships should comprise unconditional arm's-length grants with clauses limiting how corporations use health organization brands" (Freedhoff Y and PC. 2011). They warn that if we do not act we risk compromising health promotion goals by helping to promote unhealthy brands.

Awareness could be raised through counter advertising campaigns aimed at unravelling the unhealthy alliance between health charities and a company which promotes unhealthy products.

https://www.getup.org.au/campaigns/pokies-reform/grandfinal-ad/get-this-ad-on-the-air

The Get Up advocacy group has produced various counter advertising campaigns such as the one challenging the positioning of pokies in sporting clubs frequented by children. Such campaigns can be particularly effective but are often prohibitively expensive and risk defamation cases being brought against the group.

Given the significant power of the companies and their ability to scare journals, publishers and media formats, is it reasonable to revert to the type of tactics used in the Billboard Utilising Graffitists Against Unhealthy Promotions (BUGAUP) campaign? BUGAUP successfully countered tobacco advertising by adding counter slogans on the advertising by tobacco companies.

A similar idea was utilised in a recent campaign to expose Tattersall's unhealthy alliance with RCH. Members of the public used the Tattersall's advertising sign to educate the public about the hazards of gambling. Over a three month period eight messages were written, before the message was successfully conveyed and the $\mathrm{RCH}$ finally removed the sign. Whilst not advocating illegal graffiti, other legal forms of public health advocacy and protest on such important issues are important. 


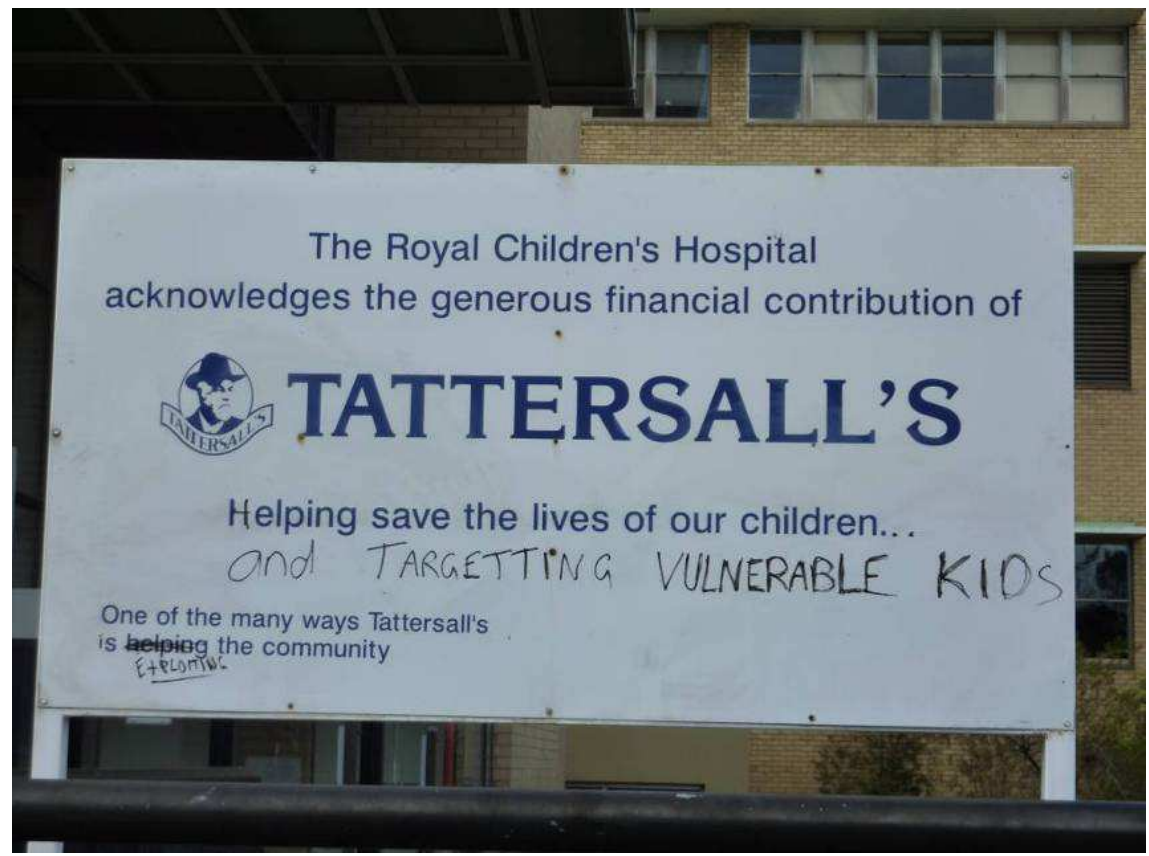

Graffiti on the sign week 2

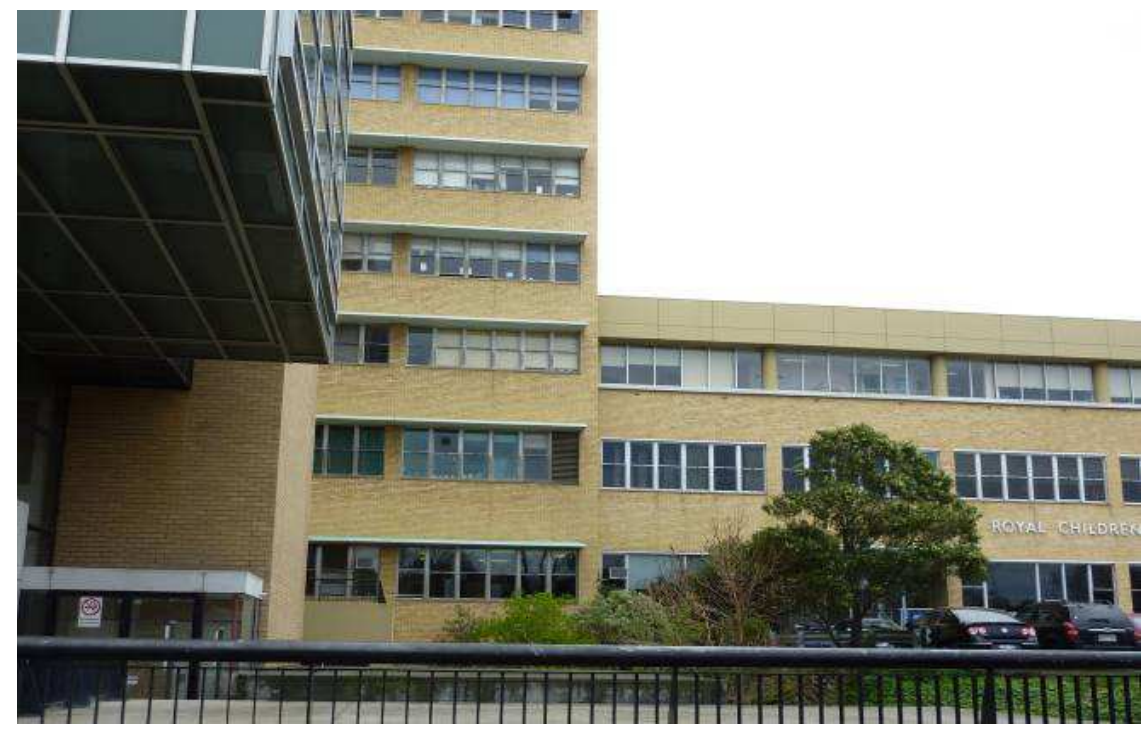

No sign (week 9) 


\section{The bigger picture}

This chapter has focussed on relevant examples from Australia where youth alcohol, childhood obesity and social problems from gambling are some of our most significant public health problems. However, this is a global problem and there are numerous examples from different countries where companies, whose product is harmful, link themselves to health organisations and health causes in order to mitigate their poor image or even to leverage support policies from these health organisations. The Canadian Medical Journal published a list of health organizations whose messages and reputations have been tarnished by partnerships with food companies (available at www.cmaj.ca/cgi/content/full/cmaj.110085/DCI ).

The common message from all these examples is that we need to be cogniscent of this tendency whereby charities are utilised, or subverted, to ultimately sell unhealthy products to our children and community. We need to question if corporate sponsorship of charities is altruistic philanthropy or merely exploitation of charities to sell what can be dangerous products? Companies may not always act so insidiously but it should be remembered that they are ultimately accountable not to public health but to their shareholders who are concerned about the bottom line.

Beyond just attaining the moral high ground there is very real danger that such companies can use their support to pressure health institutions and policy making bodies to avoid implementing healthy policies that might damage the image, and profit, of the sponsoring company. Such unhealthy alliances also help the company to lobby against important health initiatives. An editorial in the CMJ describes how the CEO of Coca-Cola, Sandy Douglas, leveraged the company's relationship with the American Academy of Family Physicians to help make the case that soda taxes were unnecessary (Freedhoff $Y$ and PC. 2011).

More recently there has been concern about corporate lobby power being brought to bear on multilateral UN agencies. An example of an unhealthy alliance with a multilateral is where UNICEF Canada, which amongst other things undertakes nutritional programs in developing countries, allowed its name to be used to promote Cadbury chocolate bars (Lancet 2010). Such partnerships are of growing concern given that changes to WHO funding mechanisms could see it receive more funding from, and work more closely with, the private sector. One commentator on the recent WHO reforms being discussed stated: "fears about WHO's independence remain as a result of the repeated calls for an increase in the role of the private sector and the possibility of funding from them". In effect the WHO would be opening itself up to a conflict of interest where the world's largest independent health watchdog and peak advisory and normative body in health, could receive funds from vested interests. If the food and beverage industry is allowed to become involved in sponsoring the WHO would it compromise the WHO's power to promote normative guidelines on obesity prevention which may involve setting limits on advertising to kids, and advising limits on salt/sugar/fat in certain foods? There is already such a precedent where food and beverage industry applied lobby pressure on powerful member states to oppose an evidence based guidelines around limits on sugar consumption. 


\section{Conclusion}

We believe that there is an ominous, and largely unquestioned, trend for unhealthy products to be co-advertised with children's health services and charities. Whilst not accusing companies of inappropriate behaviour, this viewpoint challenges regulators and health institutions themselves to reconsider unhealthy alliances. These alliances potentially advertise unhealthy products to children, give companies that produce harmful products a moral high ground of supporting children's health, and ultimately undermine important health promotion messages. We argue that such activities are ethically questionable, and using a public health framework for ethics, warrant more intrusive regulations on advertising through our children's health institutions and charities.

In the new era of public health this issue must be dealt with effectively if we are to maintain our health levels and challenge the increasing double burden of infectious and non infectious diseases in the developing world. This is the new frontline in public health and we are currently lagging behind in this conflict. This chapter, it is hoped, has helped expose potential opposition to public health and this might serve as a call to action for public health practitioners and advocates.

\section{Acknowledgments}

Dr Bruce Bolam for helping develop the concept and reviewing a number of iterations of this paper along the way.

Prof Rob Moodie for modelling a public health advocate and for the encouragement to write about such issues.

\section{References}

Australian Medical Association (2009). Alcohol Use and Harms in Australia (2009) http://ama.com.au/node/4762.

Barry, E. (2011). "No place for booze in schools fundraisers, says Australian National Council on Drugs " The Herald Sun March 2.

Cancer Council SA (2011). Public supports tougher regulation of unhealthy food advertising. Adelaide.

Center on Alcohol Marketing and Youth (2004). Youth Exposure to Alcohol Ads On TV 2002.

Centre for Behavioural Research in Cancer (2008). Australian School Students' Alcohol and Drug Survey (ASSAD) Cancer Council Victoria.

Chan, M. (2011). Tackling food-related diseases: voluntary measures or regulation - carrot or stick? . The World Health Organization's global forum: Addressing the challenge of noncommunicable diseases, Moscow.

Chapman, K., L. Hebden, et al. (2011). "Advertising of fast food to children on Australian television: the impact of industry self-regulation." Medical Journal of Australia 195(1): 20-24. 
Chikritzhs, T., P. Pascal, et al. (2004). "Under-Aged Drinking Among 14-17 Year Olds and Related Harms in Australia, National Alcohol Indicators." National Drug Research Institute, Curtin University of Technology Bulletin No.7.

Clark, D., D. Thatcher, et al. (2008). "Alcohol, psychological dysregulation and adolescent brain development." Alcoholism Clinical and Experimental Research 32(3): 375-385.

Farquharson, V. (2011, March 20). Burger King loses foothold at Sick Kids. The Globe and Mail. Toronto.

Finn, A. and J. Savulescu (2011). "Is immunisation child protection?" Lancet 378(9790): 465 - 468.

Freedhoff $Y$ and H. PC. (2011). "Parnterships between health organisaitons and the food industry risk derailing public health nutrition (editorial) " CMAJ 183(3).

Hancock, L., T. Schellinck, et al. (2008). "Gambling and corporate social responsibility (CSR): Re-defining industry and state roles on duty of care, host responsibility and risk management." Policy and society 27: 55-68.

Handsley E, Nehmy C, et al. (2007). "Media, public health and law: A lawyer's primer on the food advertising debate. ." Media and Arts Law Review 12(1): 16.

HeartKids. (2011). "Donut King supporting heartkids on valentines day." from http://www.heartkidsvic.org.au/index.php/state/news_item/donut_king_suppo rting_heartkids_on_valentines_day/

Hebden, L., L. King, et al. (2011). "Advertising of fast food to children on Australian television: the impact of industry self-regulation." Med J Aust 195(1): 20-24.

Jones, P., T. Chikritzhs, et al. (2004). "Under-Aged Drinking Among 14-17 Year Olds and Related Harms in Australia, National Alcohol Indicators." National Drug Research Institute, Curtin University of Technology, Perth. Bulletin No.7.

Lancet (2010). "Trick or treat or UNICEF Canada." Lancet 376: 1514.

Livingstone (2006). New research on advertising foods to children - an updated view of the literature, in television advertising of food and drink products to children. London, Office of Communications.

Martin, S. (2002). "Alcohol Advertising and Youth." Alcoholism: Clinical and Experimental Research 26( ): 900-906.

Mills, J. (1909). On liberty P. F. Collier \& Son.

National preventative health taskforce (2009). Australia: the healthiest country by 2020 National Preventative Health Strategy - the roadmap for action. Canberra, Commonwealth of Australia.

Needham, K. (2011 (Feb 11)). Pokies 'just like burgers'. The Age. Melbourne.

Nuffield Council on Bioethics (2007). Public health: ethical issues. London, Nuffield Council on Bioethics.

Ofcom (2008). Changes in the nature and balance of television food advertising to children: A review of HFSS advertising restrictions. London, Office of Communications.

Prisk, T. (2011). Truck drives access to health care. Centralwesterndaily.

Royal Children's Hospital. (2010). from

http:/ / www.newrch.vic.gov.au/Shopsservicesandamenities.

The Public Health Association of Australia (2008). Gambling and Health policy. Australia.

Victorian Government (2003). Gambling Regulation Act Australia 
World Advertising Research Centre. (2009). "US government to scrutinise food marketing to children." Retrieved 1 May 2010, from www.warc.com/news/topnews.asp?ID=24840. .

World Health Organization (2003). Diet, nutrition and the prevention of chronic diseases. Report of a joint WHO/FAO expert consultation. W. T. Series. Geneva, World Health Organization. 916.

Wright, K. (2010). "Corporate Social Responsibility: A Review of the Literature." The higher education academy 19(24). 


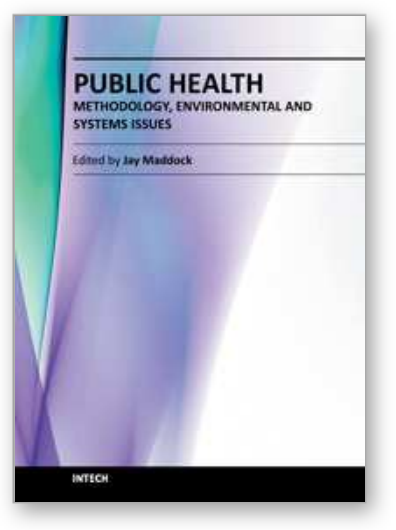

\author{
Public Health - Methodology, Environmental and Systems Issues \\ Edited by Prof. Jay Maddock
}

ISBN 978-953-51-0641-8

Hard cover, 432 pages

Publisher InTech

Published online 30, May, 2012

Published in print edition May, 2012

Public health can be thought of as a series of complex systems. Many things that individual living in high income countries take for granted like the control of infectious disease, clean, potable water, low infant mortality rates require a high functioning systems comprised of numerous actors, locations and interactions to work. Many people only notice public health when that system fails. This book explores several systems in public health including aspects of the food system, health care system and emerging issues including waste minimization in nanosilver. Several chapters address global health concerns including non-communicable disease prevention, poverty and health-longevity medicine. The book also presents several novel methodologies for better modeling and assessment of essential public health issues.

\title{
How to reference
}

In order to correctly reference this scholarly work, feel free to copy and paste the following:

Nathan Grills (2012). New Challenges in Public Health Practice: The Ethics of Industry Alliance with Health Promoting Charities, Public Health - Methodology, Environmental and Systems Issues, Prof. Jay Maddock (Ed.), ISBN: 978-953-51-0641-8, InTech, Available from: http://www.intechopen.com/books/public-healthmethodology-environmental-and-systems-issues/new-challenges-in-public-health-practice-the-ethics-ofindustry-alliance-with-health-promoting-c

\section{INTECH}

open science | open minds

\author{
InTech Europe \\ University Campus STeP Ri \\ Slavka Krautzeka 83/A \\ 51000 Rijeka, Croatia \\ Phone: +385 (51) 770447 \\ Fax: +385 (51) 686166 \\ www.intechopen.com
}

\author{
InTech China \\ Unit 405, Office Block, Hotel Equatorial Shanghai \\ No.65, Yan An Road (West), Shanghai, 200040, China \\ 中国上海市延安西路65号上海国际贵都大饭店办公楼405单元 \\ Phone: +86-21-62489820 \\ Fax: +86-21-62489821
}


(C) 2012 The Author(s). Licensee IntechOpen. This is an open access article distributed under the terms of the Creative Commons Attribution 3.0 License, which permits unrestricted use, distribution, and reproduction in any medium, provided the original work is properly cited. 